\title{
Role of gastric lavage in newborn with meconium stained amniotic fluid:A randomized controlled trail.
}

\author{
Dr. Akhilesh kumar ${ }^{1}$,Dr. Ramjee prasad gupta ${ }^{2}$,Dr. Alka singh ${ }^{3}$ \\ ${ }^{1}$ Assistant Professor, Deptt. Of Pediatrics, Nmch, Patna \\ ${ }^{2}$ Assistant Professor, Deptt. Of Pediatrics, Nmch, Patna \\ ${ }^{3}$ Head Of Department, Pediatrics, Nmch, Patna
}

\begin{abstract}
Background: Feed intolerance during early postnatal period is common in newborn with meconium stained aminotic fluid. Present study (A randomized control trail) conducted with an objective to find out incidence of feed intolerance in early postnatal period in term vigorous newborn with MSAF who received gastric lavage as compared with those who not received gastric lavage.

Method: Randomized control trail was conducted on 498 neonate born in nalanda medical college and hospital satisfying inclusion criteria. Randomally allotted 229 newborn for gastric lavage and 269 for no gastric lavage. Result: No significant difference in incidence of early post natal period vomiting was found in two group. (8\% vs $11 \%, p=0.305)$. Feed intolerance had no relationship with gender, birth weight, mode of delivery, mode of feeding. No neonates in gastric lavage group developed any complication related to procedure.

Conclusion: gastric lavage not required in newborn with meconium stained amniotic fluid.
\end{abstract}

\section{Background}

In different study incidence of meconium stained amniotic fluid (MSAF) in about 5 to $12 \%[1,2]$. Some neonate born with MSAF may swallow meconium during delivery process and develop feeding problem (nausea, vomiting) in early neonatal period because meconium act as chemical irritant to gastric mucosa. Feeding problem at first feed have been reported to be 2.8 time more frequent in neonate born with MSAF, regardless of the consistency of meconium [3].

Gastric lavage performed at birth for any indication is also not very safe procedure as it may be associated with complication like apnea, bradycardia and injury to nasal cavity, esophagus and stomach $[4,5]$. Further it can cause development of long term visceral hypersensitivity and increase prevalence of functional gastrointestinal disorder in later life [6].Previous study show that there were no significant difference in the feeding problem in neonates in whom gastric lavage performed in comprassion to those where it was not done [7-9].However gastric lavage is routinely done in our center in neonates born with MSAF without any much scientific evidence of its beneficial effect.

So present study was undertaken to know efficacy of gastric lavage in vigorous late preterm and term neonate born through MSAF in compare to those who did not receive as primary outcome measure; and also to find out any procedure related complication (apnea, bradycardia and injury to organ) as secondary outcome.

\section{Methods}

Study design: - Non-blinded randomized controlled trail carried out at department of pediatrics and obstetrics and gynecology, nalanda medical college and hospital, Patna between June 2015 to September 2016. Taking odd ratio of 2.8 , with $80 \%$ power of study and alpha error at $5 \%$, sample size calculated was found to be 462 and with addition of about $10 \%$ case lead to total of 498 cases.

Subjects:-Vigorous late preterm and term (as defined by strong respiratory effort, good muscle tone and heart rate $>100 \mathrm{bpm}$ ) neonate with gestational age $>34$ week and birth weight $>1800$ gram born through MSAF either by vaginal route or lower segment caesarean section were included. All other neonate requiring resuscitation, respiratory distress, congenital malformation was excluded. The protocol of study is approved by institute ethical committee and written informed consent was obtained from parents of each neonates included in study.

Methods:- Neonates were randomized by computer generated number in two groups: gastric lavage and non lavage group. Pediatrics resident trained in neonatal resuscitation attained the deliveries and recorded the data. Gastric lavage after routine care with $10 \mathrm{ml}$ per $\mathrm{kg}$ of normal saline was done using a $20 \mathrm{ml}$ syringe and $6 \mathrm{fr}$ nasogastric tube in aliquots of $10 \mathrm{ml}$ in neonates of gastric lavage group. Neonates in control group were not given gastric lavage. Rest of care after birth was same in both the groups. All babies were monitored for respiratory rate, heart rate, apnoea, bradycardia (HEART RATE $<80 \mathrm{bpm}$ ), cyanosis and local trauma to nostril and oral cavity due to procedure. A baseline abdominal girth was recorded. Thereafter, neonates were shifted to 
postnatal ward for rooming in and advised for exclusive breast feeding start within 30 minutes of birth as per hospital protocol, monitor for first 48 hours.

For purpose of study, vomiting was defined as expulsion of gastric contents with effort which could be projectile also. Regurgitation was defined as effortless expulsion of milk during or immediately after feeding. Criteria for feeding intolerance was adopted as reported by Ameta et al. it included more than 2 vomiting in any $4 \mathrm{~h}$ period, or $>3 \mathrm{in} 24 \mathrm{~h}$ and / or , abdominal distension is defined as increase in abdominal girth of $>2 \mathrm{~cm}$ from base line and/orogastric residual volume $>2 \mathrm{ml}$ undigested milk or bilious in colour.

\section{Statistical Analysis}

The data were analyzed using SPSS version 20. The data following Gaussian distribution, student's ttest and of non-Gaussian distribution, Mann-Whitney U test were used for comparison of two groups. For comparison of categorical variables, Chi-square test was used, and odds ratio was calculated at $95 \%$ confidence interval, A p value of $<0.05$ was considered as significant.

\section{Result}

A total of 5415 deliveries occurred and $1625(30.1 \%)$ neonates were born with MSAF during study period; only 498 (30\%) vigorous neonates were enrolled as per sample size calculation. All neonates included in this study were randomized using computer generate random numbers, 229 were allocated to GL group and 269 to no lavage group. All the patients enrolled in this study were analysed.

The basic characteristic and outcome measure are presented in Tables 1 . The baseline characteristic (mean birth weight, gestational age, gender distribution, mode of delivery, abdominal girth and median Apgar score at $5 \mathrm{~min}$ ) were comparable between the two groups. As outcome, 20(8.8\%) of GL group and 31(11.6\%) of no lavage group developed vomiting $(\mathrm{p}=0.305$, odds ratio 1.364, 95\% CL 0.754-2.463). Overall feed intolerance was found in 51 neonates and it did not differ significantly in relation to gestational age, gender, birth weight and modes of delivery. No complication of nasogastric tube insertion was observed in GL group.

\section{Discussion}

In order to avoid vomiting and subsequent aspiration of meconium and gastric content gastric lavage is routine practice in neonates with MSAF. In compare to other study incidence of MSAF in our study was higher $[2,3]$ as most of mother referred to $\mathrm{NMCH}$ in late stage. We did not find any significant difference in primary outcome in the form of vomiting or any other feed intolerance between two groups. Narchi and Kulaylat [10] reported that 4.7\%(13 of 275 neonates)of their case developed feeding problem in whom lavage was not done as compared to gastric lavage group (227 neonates) which had no feeding problem or secondary meconium aspiration. Other study reported incidence in the range of 6.8-9.7 in lavage as compared to $10.3-10.6 \%$ in no lavage group, the difference is insignificant. It may be because of the fact that vigorous neonates have less duration of exposure to meconium in utero as compared to non-vigorous. Further early feeding in post natal period dilutes the meconium and thus causes less irritation to gastrointestinal tract. Present study also shows that overall feeding intolerance also remained unchanged in relation to gestational age, gender, birth weight and mode of delivery.

No association of feeding intolerance with gender of neonates was found which is similar to the findings of Cuello-Garcia et al. [11]. By contrast, Wiswell et al. [12] documented male neonates to be more prone to have intolerance than females. No association of birth weight and gestation with feed intolerance was in accordance with the finding of Ameta et al. [7]

No procedure related complications were seen in any neonates. Thus, there is consistent evidence that GL is not of any benefit as regard to occurrence of feeding intolerance in vigorous neonates with MSAF. Despite knowing this fact still most neonatologist practice stomach wash in these neonates. [13]. This is the time that attitudinal change is required regarding this procedure. It will not only reduced the financial burden on the family by reducing the cost of consumables like nasogastric tube, syringes and normal saline but also put less work load on the paramedical staff.

The limitation of this study are that there was relatively shorter period of observation $(48 \mathrm{~h})$ during post natal period and it may be possible that some of the neonates might developed feeding intolerance after this leading to under reporting of problems. There may chance of observer bias as investigator knew the assignment group. However, we enrolled good number of cases in each arm, therefore it can be concluded that gastric lavage in neonates born with MSAF should not be.

\section{Conclusion}

As such no gastric lavage is required in vigorous neonates born through MSAF to avoid feeding intolerance. This will reduce the cost of care and save the time of paramedical staff. 


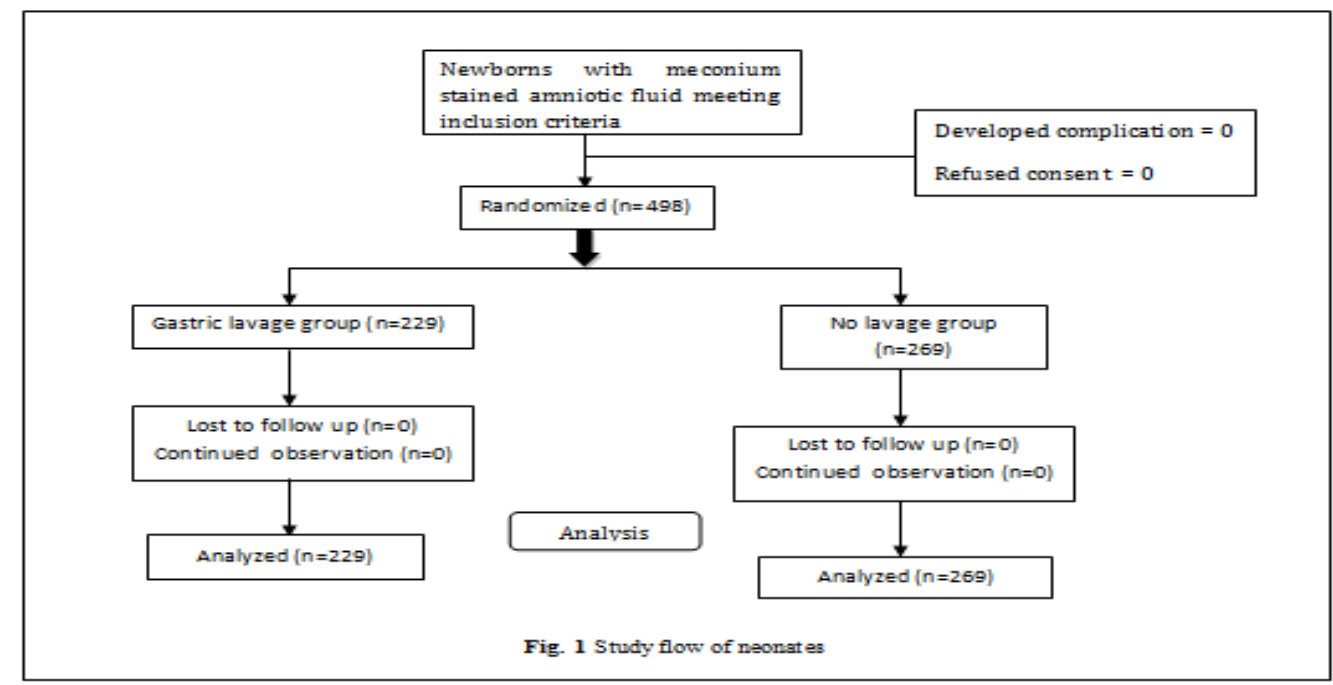

Table 1 Baseline characteristics and outcome of neonates

\begin{tabular}{|c|c|c|c|c|}
\hline \multicolumn{2}{|l|}{ Varlables } & Castric lavage group ( $n=230)$ & No lavage group $(n=270)$ & $p$-value \\
\hline \multicolumn{2}{|c|}{ Gastationalage (weeks) mean \pm} & $37.2 \pm 1.5$ & $37,4 \pm 1.4$ & $0.080 \%$ \\
\hline \multicolumn{2}{|c|}{ Birth weight (g) (mean \pm SD) } & $2746 \pm 445$ & $2795 \pm 420$ & $0.210 \%$ \\
\hline \multirow[t]{2}{*}{ Gender } & Male & $125(55 \%)$ & $130(48 \%)$ & $0.331 \%$ \\
\hline & Female & $104(45 \%)$ & $139(52 \%)$ & $0.354 * 8$ \\
\hline \multirow[t]{2}{*}{ Mode of delivery } & vaginal & $125(55 \%)$ & $156(58 \%)$ & $0.614 \% 8$ \\
\hline & LSCS & $104(45 \%)$ & $113(42 \%)$ & 0.49484 \\
\hline \multicolumn{2}{|c|}{ Apgar score m edian (IQR) 5 min } & $8(7-9)$ & $8(7-9)$ & $0.615 * 68$ \\
\hline \multicolumn{2}{|c|}{ Abdominal girth $(\mathrm{cm})$ mean $\pm S D$} & $24 \pm 0.5$ & $24 \pm 1.0$ & $0.910 \%$ \\
\hline
\end{tabular}

\section{References}

[1]. Cleary GM, Wiswell TE. Meconium-stained amniotic fluid and the meconiumaspiration syndrome.An update. Pediatr Clin North Am. 1998;45:511-29.

[2]. Wiswell TE. Handling the meconium-stained infant. Semin Neonatol.2001;6:225-31.

[3]. Narchi H, Kulaylat N. Feeding problems with the first feed in neonates withmeconium stained amniotic fluid. Paediatr Child Health. 1999;4:327-30.

[4]. Desmond MM, Rudolph AJ, Phitaksphraiwan P. The transitional care nursery.A mechanism for preventive medicine in the newborn. Pediatr Clin NorthAm. 1966;13:651-68.

[5]. Bonnard A, Carricaburu E, Sapin E. Traumatic pharyngoesophagealperforation in newborn infants. Arch Pediatr. 1997;4:737-43.

[6]. Anand KJS, Runeson B, Jacobson B. Gastric suction at birth associated withlong term risk for functional intestinal disorders in later life. J Pediatr.2004;144:449-54.

[7]. Ameta G, Upadhyay A, Gothwal S, Singh K, Dubey K, Gupta A. Role ofgastric lavage in vigorous neonates born with meconium stained amnioticfluid. Indian J Pediatr. 2013;80:195-8.

[8]. Sharma P, Nangia S, Tiwari S, Goel A, Singla B, Saili A. Gastric lavage forprevention of feeding problems in neonates with meconium-stainedamniotic fluid: a randomised controlled trial. Paediatr Int Child Health.

[9]. 2014;34:115-9.

[10]. Garg J, Masand R, Tomar BS. Utility of gastric lavage in vigorous neonatesdelivered with meconium stained liquor: A randomized controlled trial. Int JPediatr 2014, 204807, doi.org/10.1155/2014/204807

[11]. Narchi H, Kulaylat N. Is gastric lavage needed in neonates with meconiumstainedamniotic fluid? Eur J Pediatr. 1999;158:315-7.

[12]. Cuello-Garcia C, Gonzalez-lopez V, Soto-Gonzalez A, Lopez-Guevara V,Fernandez-Ortiz SJ, Cortez-Hernandez MC. Gastric lavage in healthy termnewborns: a randomized controlled trial. Anales de Pediatria.2005;63(6):509-13.

[13]. Wiswell TE, Tuggle JM, Turne BD. Meconium aspiration syndrome. Have wemade a difference? Pediatrics. 1990;85(5):715-21.

[14]. Neonatal depression at birth and resuscitation of the new born. In: LeveneM, Tudehope D, Thearle M, editors. Essential of Neonatal Medicine. 3rd ed.Oxford: Blackwell Science; 2000. p. 12-23. 